\title{
Pengaruh Parameter Shot Terhadap Kekerasan dan Kekasaran Permukaan Melalui Proses Shot-Peening Stainless Steel Tipe 316
}

\author{
M. I. Mukhsen ${ }^{1}$, R. Nur ${ }^{1,2^{*}}$ C. R. Rakka ${ }^{1}$ M. A. Fattah ${ }^{1}$ \\ ${ }^{1}$ Jurusan Teknik Mesin, Politeknik Negeri Ujung Pandang, Makassar 90245, Indonesia \\ ${ }^{2}$ Center of Materials and Manufacturing, Politeknik Negeri Ujung Pandang, Makassar 90245, Indonesia \\ rusdinur@poliupg.ac.id
}

\begin{abstract}
Type 316 stainless steel is a material that is often used in the medical world, especially as a material for making bone implant plates. However, the use of stainless steel as an implant material, stainless steel must be treated to increase the hardness and adjust the level of roughness on the surface. In this study, shot peening was carried out on the 316 stainless steel surface. The shooting parameters used were 2, 4, 6 minutes for the shooting duration, and $0^{\circ}, 15^{\circ}, 30^{\circ}, 45^{\circ}$ for the shooting angle, as well as the diameter of the steel shot used, i.e. $0.6 \mathrm{~mm}$ and $1 \mathrm{~mm}$. The results of this study indicated that there was a change in the characteristic properties of 316 stainless steel, namely the hardness and surface roughness.
\end{abstract}

Keywords: Shot parameter; Hardness; Surface roughness; shot peening; stainless steel

\begin{abstract}
Abstrak: Stainless steel tipe 316 merupakan material yang sering digunakan dalam dunia medis, terutama sebagai bahan pembuatan plat implan tulang. Akan tetapi, sebelum dapat digunakan sebagai bahan implan, stainless steel terlebih dahulu harus melalui perlakuan untuk meningkatkan kekerasan dan menyesuaikan tingkat kekasaran pada permukaan. Dalam penelitian ini, dilakukan shot peening terhadap permukaan stainless steel 316. Parameter penembakan yang digunakan yaitu 2, 4, 6 menit untuk durasi penembakan, dan $0^{\circ}, 15^{\circ}, 30^{\circ}, 45^{\circ}$ untuk sudut penembakan, serta diameter bola baja (steel shot) yang digunakan yaitu $0,6 \mathrm{~mm}$ dan $1 \mathrm{~mm}$. Hasil dari penelitian ini diperoleh bahwa terjadi perubahan pada sifat karakteristik pada permukaan stainless steel 316 yaitu tingkat kekerasan dan kekasaran permukaan.
\end{abstract}

Kata kunci : Parameter shot; Kekerasan bahan; Kekasaran permukaan; Shot peening; Stainless Steel

\section{PENDAHULUAN}

Pada kasus penyambungan tulang yang patah, material implan yang sering digunakan oleh para dokter ortopedi terbuat dari bahan titanium [1], dan stainless steel [2]. Material implan yang digunakan harus memiliki ketahanan terhadap korosi yang lebih tinggi, dikarenakan bersentuhan langsung dengan tubuh manusia [3][4]. Cairan tubuh manusia memiliki banyak ion agresif yang dapat menyebabkan korosi dan material implan juga harus mudah dibentuk agar dapat mengikuti kontur tulang manusia. Titanium merupakan bahan yang paling banyak digunakan dalam dunia medis sebagai material implan penyambung tulang yang patah [5], namun Stainless steel juga sering digunakan sebagai material implan karena merupakan bahan yang juga tahan terhadap korosi, lebih mudah dibentuk, dan biaya penggunaannya lebih murah dibanding material titanium [6]. Akan tetapi, dikarenakan tingkat kekerasan stainless steel berada di bawah material titanium, maka stainless steel perlu melalui perlakuan tambahan sebelum siap dijadikan sebagai material implan. Kadar karbon yang rendah pada stainless steel, menjadikan bahan ini sulit untuk dilakukan perlakuan panas [7], sehingga lebih disarankan untuk melalui perlakuan dingin, antara lain: proses permesinan, sandblasting [8], dan shot peening [9].

Perlakuan Shot Peening merupakan salah satu treatment yang bertujuan untuk memberikan tegangan tekan pada permukaan suatu komponen yang dapat memperbaiki sifat bahan terhadap beban dinamis. Selain dapat memperbaiki karakteristik ketahanan terhadap beban dinamis, proses shot peening juga berpengaruh terhadap karakteristik statis yang berupa kekerasan dan kekasaran bahan. 
Proses shot peening dilakukan pada wadah khusus dan penembakan bola baja menggunakan spray gun dengan tekanan udara dari mesin kompresor sebesar 4-7 bar selama beberapa menit.

Artikel ini disajikan untuk mengetahui pengaruh parameter shot (penembakan) terhadap kekerasan bahan dan kekasaran permukaan pada bahan stainless steel 316 melalui proses shot peening. Pengujian ini dilakukan dengan menvariasikan beberapa parameter, seperti: durasi penembakan, sudut penembakan dan ukuran steel shot (SS).

\section{METODE PENELITIAN}

\section{A. Bahan dan Alat yang digunakan}

Bahan yang digunakan dalam penelitian yaitu Stainless steel tipe 316 berukuran 50 x $20 \mathrm{~mm}$, ketebalan 4 mm dengan komposisi bahan yang dapat dilihat pada Tabel 1.

Tabel 1. Komposisi Stainless Steel 316

\begin{tabular}{|c|c|c|c|c|c|c|c|c|c|c|}
\hline Komposisi & $\mathrm{C}$ & $\mathrm{Mn}$ & $\mathrm{Si}$ & $\mathrm{Cr}$ & $\mathrm{Ni}$ & Mo & $\mathrm{P}$ & $\mathrm{S}$ & $\mathrm{N}$ & $\mathrm{Fe}$ \\
\hline $\begin{array}{c}\text { Persentase } \\
(\%)\end{array}$ & $\begin{array}{l}0,08 \\
\max \end{array}$ & $\begin{array}{l}2,00 \\
\max \end{array}$ & $\begin{array}{l}0,75 \\
\max \end{array}$ & $16-18$ & $10-14$ & $2-3$ & $\begin{array}{c}0,045 \\
\max \end{array}$ & $\begin{array}{l}0,03 \\
\max \end{array}$ & $\begin{array}{l}0,10 \\
\max \end{array}$ & Bal. \\
\hline
\end{tabular}

Kekasaran permukaan hasil proses shot peening diuji dengan menggunakan Surface tester Mitutoyo SJ-310 (Gambar 1), sedangkan kekerasan permukaan diuji menggunakan hardness tester AFFRI MX-206 (Gambar 2).

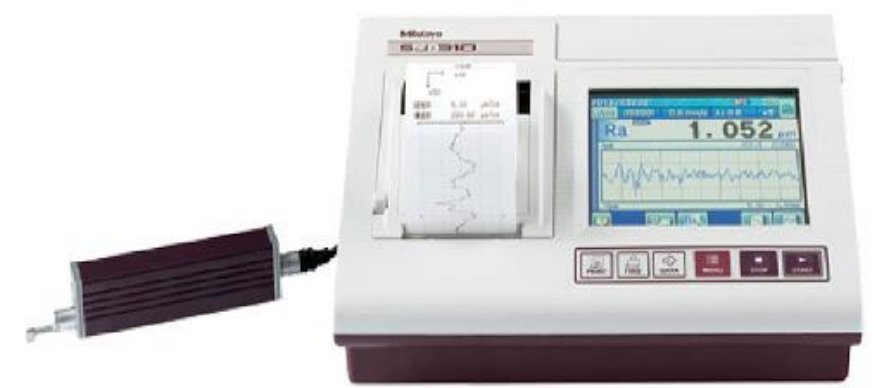

Gambar 1. Surface tester Mitutoyo SJ-310

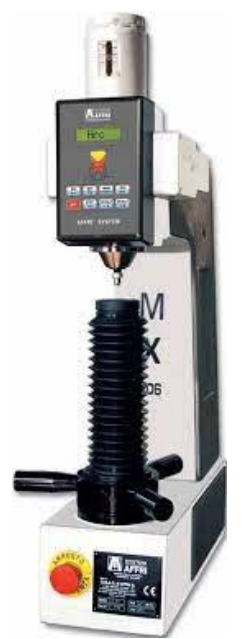

Gambar 2. Hardness tester Affri MX-206

\section{B. Paramater Shot}

Parameter penembakan (shot) yang digunakan dalam penelitian ini yaitu: 
20 M. I. Mukhsen, R. Nur, C. R. Rakka, M. A. Fattah. Pengaruh Parameter Shot Terhadap Kekerasan dan Kekasaran Permukaan Melalui Proses Shot-Peening Stainless Steel Tipe 316

Tabel 2. Parameter yang digunakan dalam proses shot peening

\begin{tabular}{|l|l|}
\hline \multicolumn{1}{|c|}{ Parameter } & \multicolumn{1}{c|}{ Range } \\
\hline Durasi Penembakan & $: 2,4,6($ menit $)$ \\
\hline Sudut Penembakan & $: 0^{\circ}, 15^{\circ}, 30^{\circ}, 45^{\circ}$ \\
\hline Steel Shot $(\mathrm{SS})$ & $: 0,6$ dan $1(\mathrm{~mm})$ \\
\hline
\end{tabular}

\section{HASIL DAN PEMBAHASAN}

\section{A. Pengaruh Parameter Shot terhadap Kekasaran Permukaan}

Hasil pengujian kekasaran permukaan pada benda uji sebelum dan sesudah penembakan dapat dilihat pada Tabel 3 .

Tabel 3. Hasil Pengujian Kekasaran permukaan (Ra) pada Proses Shot Peening

\begin{tabular}{|c|c|c|c|c|c|}
\hline \multirow{2}{*}{$\begin{array}{c}\text { Sudut } \\
\text { Penembakan }\end{array}$} & $\begin{array}{c}\text { Diameter Steel } \\
\text { Shot }(\mathrm{mm})\end{array}$ & \multicolumn{4}{|c|}{ Ra $(\mu \mathrm{m})$} \\
\cline { 2 - 6 } & & $0 \mathrm{~s}$ & $120 \mathrm{~s}$ & $240 \mathrm{~s}$ & $360 \mathrm{~s}$ \\
\hline \multirow{2}{*}{$0^{\circ}$} & 0.6 & 3.31 & 1.71 & 1.54 & 1.37 \\
\cline { 2 - 6 } & 1 & 3.31 & 1.98 & 1.69 & 1.57 \\
\hline \multirow{2}{*}{$15^{\circ}$} & 0.6 & 3.31 & 1.84 & 1.53 & 1.51 \\
\cline { 2 - 6 } & 1 & 3.31 & 2.08 & 1.73 & 1.56 \\
\hline \multirow{2}{*}{$30^{\circ}$} & 0.6 & 3.31 & 1.70 & 1.56 & 1.53 \\
\cline { 2 - 6 } & 1 & 3.31 & 1.74 & 1.59 & 1.55 \\
\hline \multirow{2}{*}{$45^{\circ}$} & 0.6 & 3.31 & 1,77 & 1,59 & 1,49 \\
\cline { 2 - 6 } & 1 & 3.31 & 1,91 & 1,64 & 1,51 \\
\hline
\end{tabular}

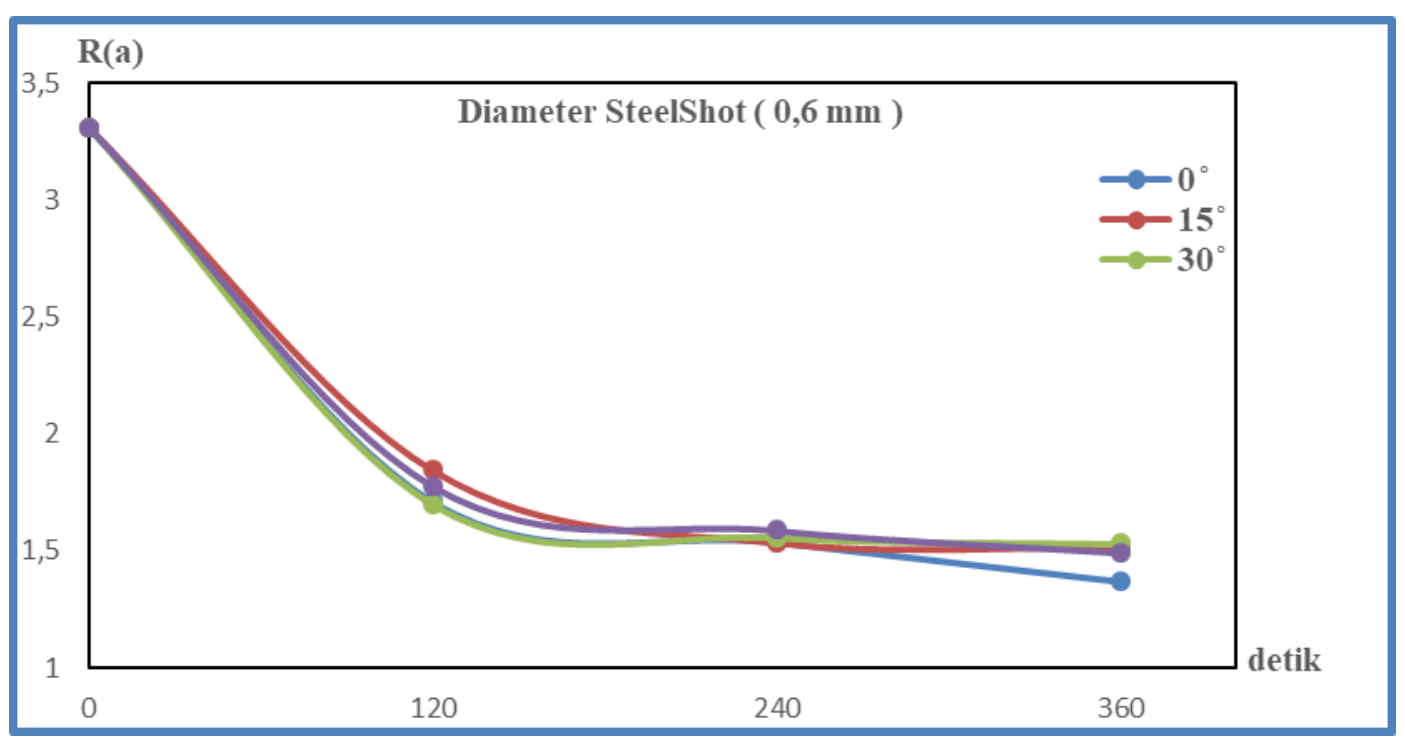

Gambar 1. Kekasaran permukaan hasil penembakan dengan SS 0.6 mm 


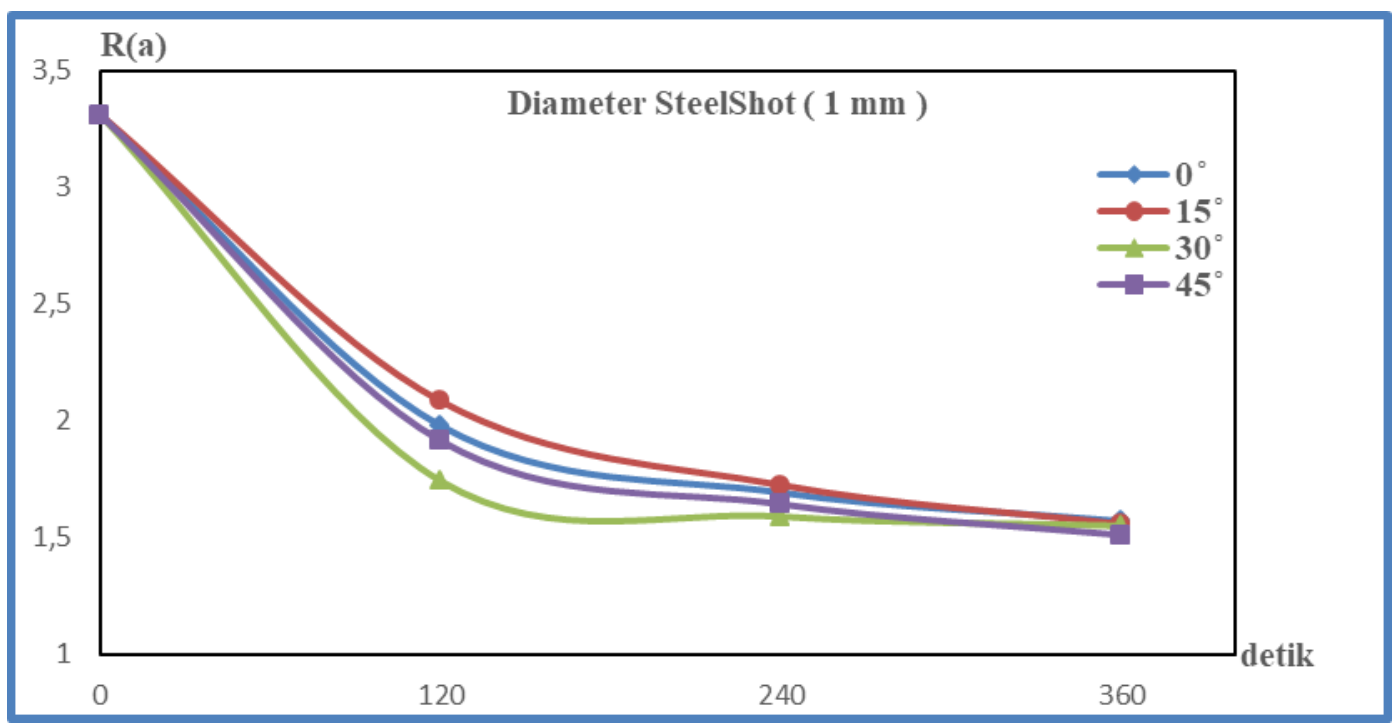

Gambar 2. Kekasaran Permukaan hasil Penembakan dengan SS 1 mm

Pada Gambar 1 dan Gambar 2, ditunjukkan perbandingan hasil uji kekasaran antara sejumlah spesimen yang mengalami proses penembakan dengan 2 jenis diameter steel shot yang berbeda $(\varnothing 0,6$ $\mathrm{mm}$ dan $\varnothing 1 \mathrm{~mm}$ ). Dari grafik dapat disimpulkan bahwa seluruh spesimen mengalami penurunan kekasaran yang sangat signifikan pada penembakan awal selama 120 detik. Kemudian pada penembakan selama 240 detik, seluruh spesimen terus mengalami penurunan meskipun tidak terlalu signifikan. Dan pada penembakan selama 360 detik, seluruh spesimen terus mengalami penurunan dengan hasil akhir rata-rata kekasaran nyaris sama atau saling berdekatan. Hal ini menunjukkan bahwa kekasaran permukaan pada stainless steel 316 akan semakin halus jika durasi proses shot peening semakin lama. Hasil yang sama juga telah dilakukan dalam meneliti pengaruh kondisi penembakan terhadap kekasaran permukaan pada proses shot peening stainless steel [10]. Penelitian lain juga menyimpulkan bahwa terdapat penurunan parameter kekasaran permukaan Sa, Sq, S5z dan Sku pada proses shot peening 18CrNiMo7-6 steel [11].

\section{B. Pengaruh Parameter Shot terhadap Kekerasan Bahan}

Hasil pengujian kekerasan bahan pada benda uji sebelum dan sesudah penembakan dapat dilihat pada Tabel 4.

Tabel 4. Hasil Pengujian Kekerasan bahan (HBN) pada Proses Shot Peening

\begin{tabular}{|c|c|c|c|c|c|}
\hline \multirow{2}{*}{$\begin{array}{c}\text { Sudut } \\
\text { Penembakan }\end{array}$} & $\begin{array}{c}\text { Diameter Steel } \\
\text { Shot }(\mathrm{mm})\end{array}$ & \multicolumn{4}{|c|}{ HBN $\left(\mathrm{kgf} / \mathrm{mm}^{2}\right)$} \\
\cline { 3 - 6 } & & $0 \mathrm{~s}$ & $120 \mathrm{~s}$ & $240 \mathrm{~s}$ & $360 \mathrm{~s}$ \\
\hline \multirow{2}{*}{$0^{\circ}$} & 0.6 & 112,55 & 162,60 & 164,20 & 167,83 \\
\cline { 2 - 6 } & 1 & 112,55 & 162,33 & 162,91 & 167,04 \\
\hline \multirow{2}{*}{$15^{\circ}$} & 0.6 & 112,55 & 164,07 & 165,55 & 168,58 \\
\cline { 2 - 6 } & 1 & 112,55 & 150,83 & 159,08 & 166,36 \\
\hline \multirow{2}{*}{$30^{\circ}$} & 0.6 & 112,55 & 159,26 & 165,88 & 167,25 \\
\cline { 2 - 6 } & 1 & 112,55 & 144,94 & 152,63 & 156,22 \\
\hline \multirow{2}{*}{$45^{\circ}$} & 0.6 & 112,55 & 157,54 & 166,14 & 168,00 \\
\cline { 2 - 6 } & 1 & 112,55 & 148,99 & 162,28 & 163,44 \\
\hline
\end{tabular}


22 M. I. Mukhsen, R. Nur, C. R. Rakka, M. A. Fattah. Pengaruh Parameter Shot Terhadap Kekerasan dan Kekasaran Permukaan Melalui Proses Shot-Peening Stainless Steel Tipe 316

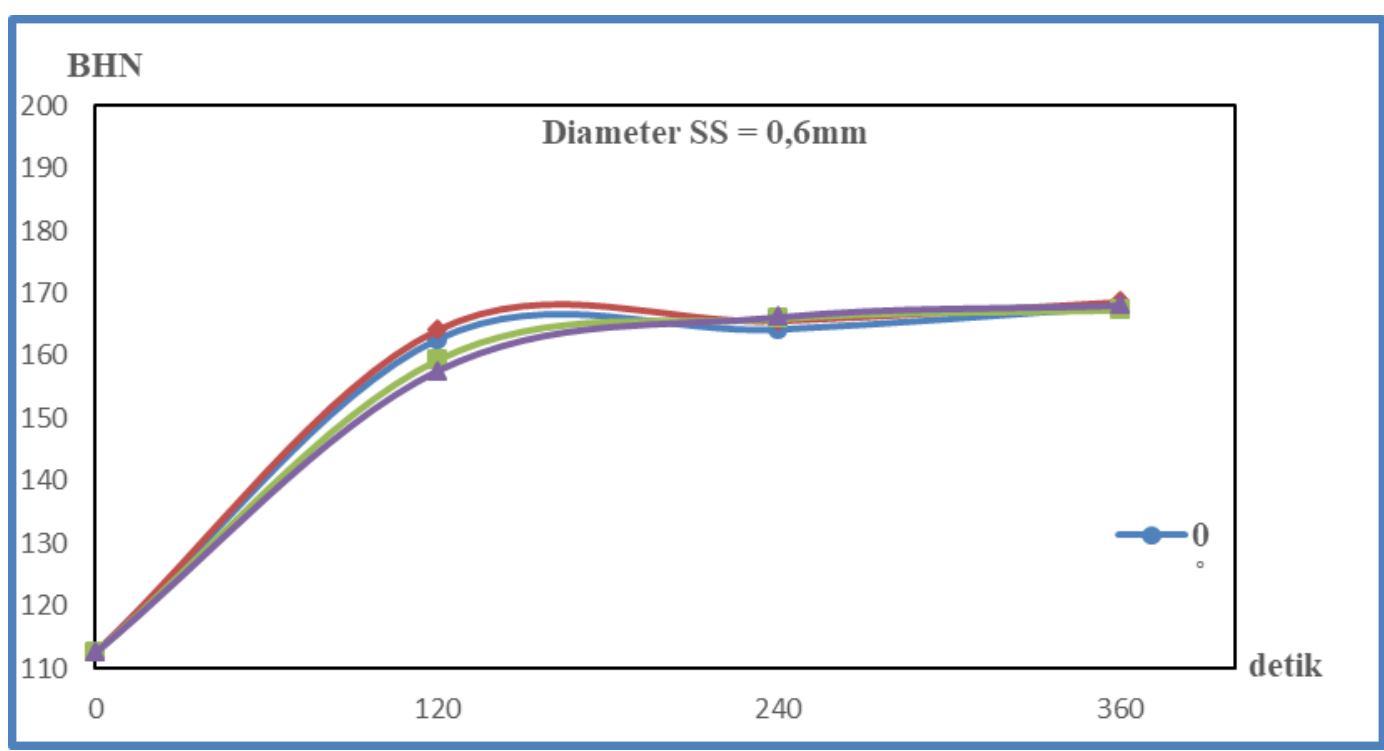

Gambar 3. Kekerasan Permukaan dengan Penembakan SS menggunakan 0,6 mm

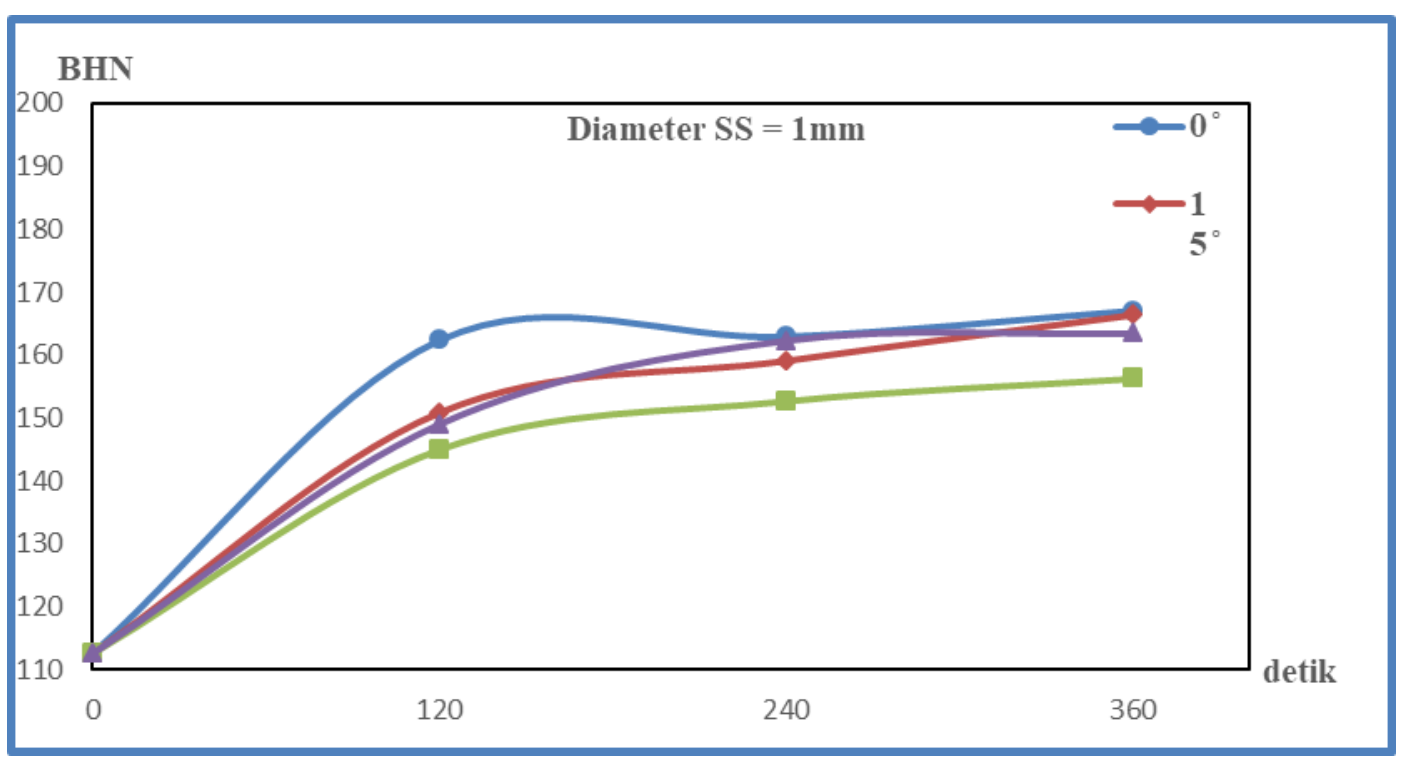

Gambar 4. Kekerasan Permukaan dengan Penembakan menggunakan SS 1 mm

Pada Gambar 3 dan Gambar 4, diperlihatkan perbandingan hasil uji kekerasan antara sejumlah spesimen yang mengalami proses penembakan dengan 2 jenis diameter steel shot yang berbeda $(\varnothing 0,6$ $\mathrm{mm}$ dan $\varnothing 1 \mathrm{~mm}$ ). Dari grafik dapat disimpulkan bahwa seluruh spesimen mengalami peningkatan kekerasan yang sangat signifikan pada penembakan awal selama 120 detik. Kemudian pada penembakan selama 240 detik, seluruh spesimen terus mengalami peningkatan kekerasan meskipun tidak terlalu signifikan. Dan pada penembakan selama 360 detik, seluruh spesimen terus mengalami peningkatan dengan hasil akhir rata-rata kekerasan nyaris sama atau saling berdekatan. Hasil ini menunjukkan bahwa kekerasan bahan akan meningkat pada saat proses shot peening dilakukan hingga durasi semakin lama. Hasil ini juga diperkuat dengan penelitian yang menemukan bahwa shot peening telah mempromosikan penyempurnaan butir dan meningkatkan kekerasan permukaan rol karburasi 
[12]. Penelitian lain juga menyimpulkan bahwa kekerasan permukaan hasil treatment USP (Ultrasonic Shot Peening) pada titanium telah meningkat secara signifikan [13].

\section{KESIMPULAN}

Kesimpulan dari hasil penelitian dijelaskan pada bagian ini

a. Tingkat kekasaran terendah dihasilkan melalui proses Shot Peening menggunakan steel shot $\varnothing 0,6$ mm selama 6 menit, dengan sudut penembakan $0^{\circ}$ dengan nilai kekasaran yaitu 1,37 $\mu \mathrm{m}$. Sedangkan tingkat kekerasan terbaik dihasilkan melalui proses Shot Peening menggunakan steel shot $\varnothing 0,6 \mathrm{~mm}$ selama 6 menit, dengan sudut penembakan $15^{\circ}$ dengan nilai kekerasan yaitu $168,58 \mathrm{kgf} / \mathrm{mm}^{2}$.

b. Steel Shot berdiameter 0,6 mm lebih banyak berpengaruh baik itu terhadap kekasaran dan kekerasan spesimen uji. Dapat dilihat bahwa hasil penembakan spesimen dengan menggunakan Steel Shot 0,6 mm menghasilkan kekasaran yang lebih rendah dibandingkan dengan penembakan menggunakan Steel Shot $1 \mathrm{~mm}$, dan hal ini juga berlaku pada hasil uji kekerasan spesimen didapatkan bahwa spesimen dengan penembakan menggunakan Steel Shot 0,6 mm lebih keras dibandingkan menggunakan Steel Shot $1 \mathrm{~mm}$.

c. Semakin lama penembakan dilakukan, maka akan menghasilkan spesimen yang lebih baik, baik dalam tingkat kekasaran maupun tingkat kekerasan. Namun perlu diketahui bahwa, pada penembakan selama 2 menit sudah menghasilkan perubahan yang sangat drastis terhadap spesimen, akan tetapi jika ingin mendapatkan spesimen yang lebih baik, bisa melakukan penembakan lebih lama hingga 4 - 6 menit hingga mendapat tingkat kekasaran dan kekerasan yang diharapkan.

d. Stainless Steel 316 dapat dijadikan sebagai bahan dasar lain dalam proses pembuatan implan tulang pengganti titanium, namun harus melalui perlakuan terlebih dahulu sebelum siap digunakan.

\section{DAFTAR PUSTAKA}

[1] E. B. Taddei, V. A. R. Henriques, C. R. M. Silva, and C. A. A. Cairo, "Production of new titanium alloy for orthopedic implants," Mater. Sci. Eng. C, vol. 24, no. 5, pp. 683-687, 2004.

[2] B. Gervais, A. Vadean, M. Raison, and M. Brochu, "Failure analysis of a 316L stainless steel femoral orthopedic implant," Case Stud. Eng. Fail. Anal., vol. 5, pp. 30-38, 2016.

[3] N. J. Hallab, R. M. Urban, and J. J. Jacobs, "Corrosion and biocompatibility of orthopedic implants," Biomater. Orthop., pp. 63-92, 2004.

[4] G. Manivasagam, D. Dhinasekaran, and A. Rajamanickam, "Biomedical implants: corrosion and its prevention-a review.," Recent patents Corros. Sci., 2010.

[5] K. Pałka and R. Pokrowiecki, "Porous titanium implants: a review," Adv. Eng. Mater., vol. 20, no. 5, p. 1700648, 2018.

[6] N. Godbole, S. Yadav, M. Ramachandran, and S. Belemkar, "A review on surface treatment of stainless steel orthopedic implants," Int J Pharm Sci Rev Res, vol. 36, no. 1, pp. 190-194, 2016.

[7] M. Turski, S. Clitheroe, A. D. Evans, C. Rodopoulos, D. J. Hughes, and P. J. Withers, "Engineering the residual stress state and microstructure of stainless steel with mechanical surface treatments," Appl. Phys. A, vol. 99, no. 3, pp. 549-556, 2010.

[8] P. Horodek, M. K. Eseev, and A. G. Kobets, "Studies of stainless steel exposed to sandblasting," Nukleonika, vol. 60, 2015.

[9] R. Gopi, I. Saravanan, and A. Devaraju, "Investigation of shot peening process on stainless steel and its effects for tribological applications," Mater. Today Proc., vol. 22, pp. 580-584, 2020.

[10] M. I. Mukhsen, R. Nur, M. A. Af Yusuf, and C. Rakka, "The influence of shooting conditions during shot peening of stainless steel on surface roughness," in IOP Conference Series: Materials Science and Engineering, 2020. 
24 M. I. Mukhsen, R. Nur, C. R. Rakka, M. A. Fattah. Pengaruh Parameter Shot Terhadap Kekerasan dan Kekasaran Permukaan Melalui Proses Shot-Peening Stainless Steel Tipe 316

[11] J. Wu, H. Liu, P. Wei, Q. Lin, and S. Zhou, "Effect of shot peening coverage on residual stress and surface roughness of 18CrNiMo7-6 steel," Int. J. Mech. Sci., vol. 183, p. 105785, 2020.

[12] J. Wu, H. Liu, P. Wei, C. Zhu, and Q. Lin, "Effect of shot peening coverage on hardness, residual stress and surface morphology of carburized rollers," Surf. Coatings Technol., vol. 384, p. $125273,2020$.

[13] L. Zhu, Y. Guan, Y. Wang, Z. Xie, and J. Lin, "Influence of process parameters of ultrasonic shot peening on surface nanocrystallization and hardness of pure titanium," Int. J. Adv. Manuf. Technol., vol. 89, no. 5-8, pp. 1451-1468, 2017. 